\title{
FORMULATION AND IN VITRO, IN VIVO EVALUATION OF PRONIOSOMAL GEL OF NEOMYCIN SULPHATE
}

\author{
AMOL SHETE ${ }^{1}$, PRIYANKA THORAT ${ }^{2}$, RAJENDRA DOIJAD ${ }^{1}$, SACHIN SAJANE ${ }^{3}$
}

1Department of Pharmaceutics, Krishna Institute of Pharmacy of Krishna Institute of Medical Sciences Deemed To Be University, Karad, 415110, India, ${ }^{2}$ Research Group Department of Pharmaceutics and Quality Assurance, Shree Santkrupa College of Pharmacy, Ghogaon, Karad 415111, MS, India, ${ }^{3}$ Department of pharmacology, Annasaheb Dange College of pharmacy, Ashta, Maharashtra. India Email: amol.shete@rediffmail.com

Received: 01 Nov 2018, Revised and Accepted: 30 Jan 2019

ABSTRACT

Objective: The objectives of present investigation were to prepare and evaluate proniosomes of neomycin sulphate (NS) by coacervation phase separation method by using sorbitan monostearate (span 60) and lecithin as a surfactant to increase the penetration through the skin and study the effect of concentration of the same.

Methods: Proniosomes of neomycin sulphate (NS) were prepared by coacervation phase separation method by using span 60 and lecithin. The effect of concentration of span 60 and lecithin was studied by factorial design. The prepared proniosomes were converted to gel by using carbopol as a gelling agent. The prepared formulations were evaluated for entrapment efficiency, in vitro drug diffusion, in vitro antibacterial activity and in vivo skin irritation test etc.

Results: All Formulation showed the percentage entrapment efficiency in the range $38.31 \pm 0.05 \%$ to $77.96 \pm 0.06 \%$, good homogeneity and gel was easily spreadable with minimal of shear. Optimized formulation showed enhanced rate of diffusion in vitro, increase in zone of inhibition against staphylococcus aureus, no skin irritation and showed good stability.

Conclusion: The results of present study indicates that proniosomal gel formulated by using combination of span 60 , Lecithin, cholesterol can be used to enhance skin delivery of NS because of excellent permeation of drug. Developed proniosomal gel formulation was promising carrier for NS

Keywords: Proniosomes, Neomycin Sulphate, Sorbitane monostearate (span 60), Lecithin and Cholesterol

(C) 2019 The Authors. Published by Innovare Academic Sciences Pvt Ltd. This is an open access article under the CC BY license (http://creativecommons.org/licenses/by/4.0/) DOI: http://dx.doi.org/10.22159/ijap.2019v11i2.30614

\section{INTRODUCTION}

Oral route of administration is most accepted route for majority of drugs but still faces challenges as compared to other routes. Transdermal route gives better control of blood level, reduce systemic toxicity, it protects drug from the hepatic first pass metabolism, better patient compliance and can be a potential option for oral dosage forms. Human skin is the important target site for the application of drug especially in the treatment of local disease. Penetration enhancement with special formulation approaches is mainly based on the usage of colloidal carriers [1]. Colloidal carrier have distinct advantages over conventional drug delivery as it act as drug containing reservoirs, modification of the particle composition or surface can adjusts the release rate to the target site [2]. These carriers accumulate in stratum corneum or other upper skin layers and are not expected to penetrate into viable skin. The penetration enhancement is the most critical factor in the transdermal drug delivery [3]. Hence it is necessary to increase the flux through skin membrane by using different approaches of penetration enhancement. Vesicular systems have been widely studied as vehicles for dermal and transdermal drug delivery. A number of vesicles systems such as liposomes, niosomes, ethosomes, emulsomes and transfersomes have been developed. The vesicular carrier such as niosomes has distinct advantage over conventional dosage forms because these particles can act as drug reservoir [1-2].

Compounds having high molecular weight cannot cross skin, need some amendment owing to the availability of novel methods that might enhance the transport of large molecular weight compounds into or through the skin. Vesicular systems especially niosomes and liposomes are well established system for the transdermal route but the stabilityis the major problem of these carriers. Liposome exhibits some difficulties such as instability of aqueous dispersions on storage and the leakage of the encapsulated drugs. Also the high cost of synthetic phospholipids.

An alternative approach i.e. niosomes that overcomes several of these problems associated with liposomes [3]. Non-ionic surfactant vesicles obtained on hydration of synthetic non-ionic surfactants, with or without incorporation of cholesterol or other lipid [4]. But the proniosomes are more advantageous than nonionic surfactant vesicles i.e., niosomes, in terms of physical stability such as aggregation, fusion and leaking, and provide additional convenience in transportation, distribution, storage, and dosing [5]. Proniosomes encloses both hydrophilic and lipophilic drugs. Proniosomes reduce the toxicity related to drug because of their non-ionic nature of surfactant [6].

Neomycin Sulphate is a bactericidal aminoglycoside antibiotics (or antibacterial agent) is categorized as a BCS class-III i.e. high solubility and poor permeability, and generally it used as topical agent in skin infection. Physicochemical properties of NS like highly polar nature and high molecular weight (908.87D). Poor skin permeability $(<3 \%)$ of Neomycin sulphate reduces its deeper penetration in skin [7]. That aminoglycoside antibiotic works by binding to the bacterial $30 \mathrm{~S}$ ribosomal subunit, causing misreading of t-RNA, leaving the bacterium unable to synthesize proteins vital to its growth [8-10]. In present investigation proniosomal gel of NS was prepared by using span 60 and lecithin to increase the skin penetration.

\section{MATERIALS AND METHODS}

\section{Materials}

Neomycin Sulphate was obtained as a gift sample from Encube Ethical Pvt. Ltd. Goa. Span 60, Cholesterol and carbopol 934 were purchased from Loba Chemicals, Mumbai. Lecithin was purchased from Research lab Mumbai. All other ingredients were of analytical grade.

\section{Formulation of proniosomal gel}

Proniosomes were prepared by the modified literature method reported by Fang et al. 2001 [11]. Proniosomes prepared by coacervation phase separation method. Precisely weighed amount of drug, surfactant, cholesterol, lecithin, and organic solvent (Ethanol) taken in wide mouth container. After mixing all ingredients, the open end of glass tube was covered with a lid to prevent loss of solvent from it and warmed on water bath at $60-70{ }^{\circ} \mathrm{C}$ for about 10 min, until the surfactants were dissolved completely. Then aqueous 
phase Phosphate buffer $\mathrm{pH} 7.4$ was added and the mixture was further warmed in the water bath for about 2 min. so that a clear solution was obtained. The mixture was allowed to cool to room temperature until the dispersion was converted to proniosomal gel. Carbopol 934 was added in formulation in 1:1 ratio.

\section{Effect of variables}

To study the effect of variables by using $3^{2}$ factorial designs was applied for optimization of proniosomal gel formulation shown in table 1. In this study two factors were evaluated each at three levels and experimental trials were performed at all nine possible combinations. The amount of surfactant and lecithin were selected as independent variables. The percentage entrapment efficiency and percentage drug release was selected as dependent variables. Here the cholesterol concentration was kept constant at $10 \%$ because of the concentration of cholesterol above $10 \%$ then it might lead to decreases $\%$ entrapment efficiency and forms more rigid bilayer and also decrease $\%$ drug release [12].

Table 1: Composition of formulation

\begin{tabular}{llllll}
\hline S. No. & Formulation code & Drug (mg) & Surfactant span 60 (mg) & Lecithin (mg) \\
\hline 1 & PG1 & 5 & 0.7 & 0.2 & 0.5 \\
2 & PG2 & 5 & 0.7 & 0.8 & 0.1 \\
3 & PG3 & 5 & 0.7 & 0.2 & 0.1 \\
4 & PG4 & 5 & 0.4 & 0.5 & 0.1 \\
5 & PG5 & 5 & 0.4 & 0.8 & 0.1 \\
6 & PG6 & 5 & 0.4 & 0.2 & 0.1 \\
7 & PG7 & 5 & 0.1 & 0.5 & 0.1 \\
8 & PG8 & 5 & 0.1 & 0.8 & 0.1 \\
9 & PG9 & 5 & 0.1 & & 0.1 \\
\hline
\end{tabular}

\section{Physical evaluation of gels}

The prepared gel formulations were evaluated for physical appearance, $\mathrm{pH}$, homogeneity, spread ability and viscosity by using conventional digital R/S plus Rheometer Brookfield Engineering Lab Inc. (USA)

\section{Microscopic evaluation}

In glass tube, $0.2 \mathrm{gm}$ proniosomal gel of all formulation was diluted with $10 \mathrm{ml}$ of $\mathrm{pH} 7.4$ phosphate buffer; few drop of formed niosomal dispersion were spread on a glass slide and examined for the vesicles structure using ordinary light microscope with varied magnification power. Photomicrographs were taken for niosomes at 100X.

\section{Entrapment efficiency}

It was determined indirectly i.e. by calculating the amount of unentrapped drug as shown in equation 1 . To $0.2 \mathrm{~g}$ of proniosome gel $10 \mathrm{ml}$ of phosphate buffer $\mathrm{pH} 7.4$ was added. The niosomes were separated from untrapped drug by centrifugation at $5000 \mathrm{rpm}$ for $30 \mathrm{~min}$ and evaluating the supernatant spectrophotometrically (Shimadzu-1601, Tokyo) at $277 \mathrm{~nm}$ with suitable dilution.

Entrapment efficiency was calculated by using following formula,

$$
\% \text { Entrapment Efficiency }=(C t-C r) / C r x 100 \text {................... } 1
$$

Where, $\mathrm{Ct}=$ Concentration of total drug, $\mathrm{Cr}=$ Concentration of free drug

\section{Vesicle size analysis}

Particle size and zeta potential of formulation was determined by using Malvern Zetasizer instrument v2.1.

\section{In vitro ex-vivo permeation study}

These studies were performed using locally Fabricated KesharyChientype diffusion cell with an area of $2.1 \mathrm{~cm}^{2}$ (Sigma, Inc. Mo. USA). The capacity of receptor compartment was $20 \mathrm{ml}$. The dialysis membrane and human cadaver skin was mounted between the donor and receptor compartment. A weighed amount of proniosomal gel was placed on one side of the membrane. The receptor medium was containing phosphate buffer $\mathrm{pH} 7.4$ with continuous rotation speed of $50 \mathrm{rpm}$ by using magnetic stirrer. The receptor compartment was surrounded by a water jacket to maintain the temperature at $37 \pm 0.5^{\circ} \mathrm{C}$. At each sampling interval during $24 \mathrm{~h}, 1$ mlwas withdrawn and was replaced by equal volumes of fresh receptor fluid on each occasion. Samples withdrawn were analyzed by UV-visible double beam spectrophotometer (Shimadzu1601 , Tokyo) at $277 \mathrm{~nm}$ by using furfural assay of NS [5].

\section{Drug release kinetics}

The release data obtained from various formulations werestudied further for their fitness of data in different kineticmodels like zero order, first order, Higuchi model, Hixoncrowell and Korsemeyer peppa's model.

\section{In vitro antimicrobial activity}

This study was carried out by using Agar-cup diffusion method and Staphylococcus Aureus culture was used. The nutrient agar broth was used as a media. The subculture of Staphylococcus Aureus culture was spread in petri-dish. (Bacterial strains were obtained from faculty of allied sciences, Microbiology and Biotechnology KIMSDTU, Karad) On solidification, $1 \mathrm{~cm}$ holes were made and filled with a formulation. The one plate hole filled with pure NS solution, second plate hole filled with marketed NS cream formulation

\section{Stability studies}

The ability of vesicles to retain the drug was assessed by keeping the proniosomal gel at ambient temperature. Throughout the study, proniosomal formulations were stored in stoppered glass vials. Entrapment efficiency of formulations were determined before and after completion of one month and measurement were made by spectrophotometer(Shimadzu-1601, Tokyo) at $277 \mathrm{~nm}$

\section{Skin irritation study}

The skin irritation studies was performed using healthy albino Wistar rats (220-300 gm) obtained from TKCP Warnanagar and were housed in polypropylene cages, with laboratory diet and water. Animals were acclimatized for period of $24 \mathrm{~h}$ to ensure their suitability for Study. The dorsal abdominal skin of rats was shaved $24 \mathrm{~h}$ before study. Optimized proniosomal gel was applied on dorsal skin and application site was occluded with gauze and covered with a nonsensitzing micro porous tapes. After $24 \mathrm{~h}$ the formulation was removed, and development of erythema was recorded [Approval Letter no. IAEC/TKCP/2014/13].

\section{RESULTS AND DISCUSSION}

The physical appearance of the gel was observed by eyes. All proniosomal gel formulations were yellowish in colour as shown in table 2. It might be due to brown colour of soya lecithin [7].

The $\mathrm{pH}$ of all formulations was found in ranged from 6.5-7.1 given in table 2 and that $\mathrm{pH}$ suitable to skin $\mathrm{pH}$ [13]. It reveales that the formulations will be compatible with skin.

All developed proniosomal gel formulations showed good homogeneity with absence of lumps (table 2). The value of spreadability of all proniosomal formulations ranged from $4.5 \pm 0.01$ to $6.9 \pm 0.02(\mathrm{~g} . \mathrm{cm} / \mathrm{sec})$ shown in table 2 . The value of spreadability indicate that the gel is easily spreadable with minimal of shear [14].

\section{Viscosity determination}

All proniosomal gel formulations were semisolid in consistency as required for skin application except the PG9 formulation, which had softer consistency (table 2). The consistency of the gel increased 
because of the molecular interaction of polar head groups of surfactant with the solvent and permeation of solvent into the bilayers. The solvent diffusion into the bilayers did not disturb the liquid crystalline structure. It results in complete bilayer formation due to the saturation of the lipid polar heads. This might have lead to an increase in bilayers distance resulting in an overall increase in consistency [15]. One another reason of increased consistency due to the loss of alcohol upon storage $[14,15]$.

Table 2: Physical characterization of proniosomal gel

\begin{tabular}{llllll}
\hline S. No. & Formulation code & Appear-ance & pH* & Homoge- neity & Spreadability* (g. cm/sec) \\
\hline 1 & PG1 & Yellowish & $6.8 \pm 0.02$ & Good & $4.5 \pm 0.01$ \\
2 & PG2 & Yellowish & $6.9 \pm 0.05$ & Good & $5.1 \pm 0.05$ \\
3 & PG3 & Yellowish & $7.1 \pm 0.01$ & Good & $5.3 \pm 0.03$ \\
4 & PG4 & Yellowish & $6.5 \pm 0.03$ & Good & $4.7 \pm 0.02$ \\
5 & PG5 & Yellowish & $6.7 \pm 0.06$ & Good & $391.68 \pm 0.01$ \\
6 & PG6 & Yellowish & $6.9 \pm 0.03$ & Good & $354.82 \pm 0.03$ \\
7 & PG7 & Yellowish & $6.9 \pm 0.02$ & Good & $6.6 \pm 0.04$ \\
8 & PG8 & Yellowish & $7.0 \pm 0.01$ & Good & $6.7 \pm 0.03$ \\
9 & PG9 & Yellowish & $6.9 \pm 0.04$ & Good & $6.7 \pm 0.05$ \\
\hline
\end{tabular}

*Above values indicate mean \pm SD $(n=3)$

\section{Microscopic determination}

After hydration of proniosomes by using phosphate buffer the niosomal suspension was formed which was seen under the microscope. The photomicrographs of all formulations are shown in fig. 1. Most of vesicles are well identified; spherical in shape having large internal aqueous space niosomes were observed. Addition of water with polar groups of surfactant. In presence of excess of water there was complete hydration leading to formation of niosomes [16].

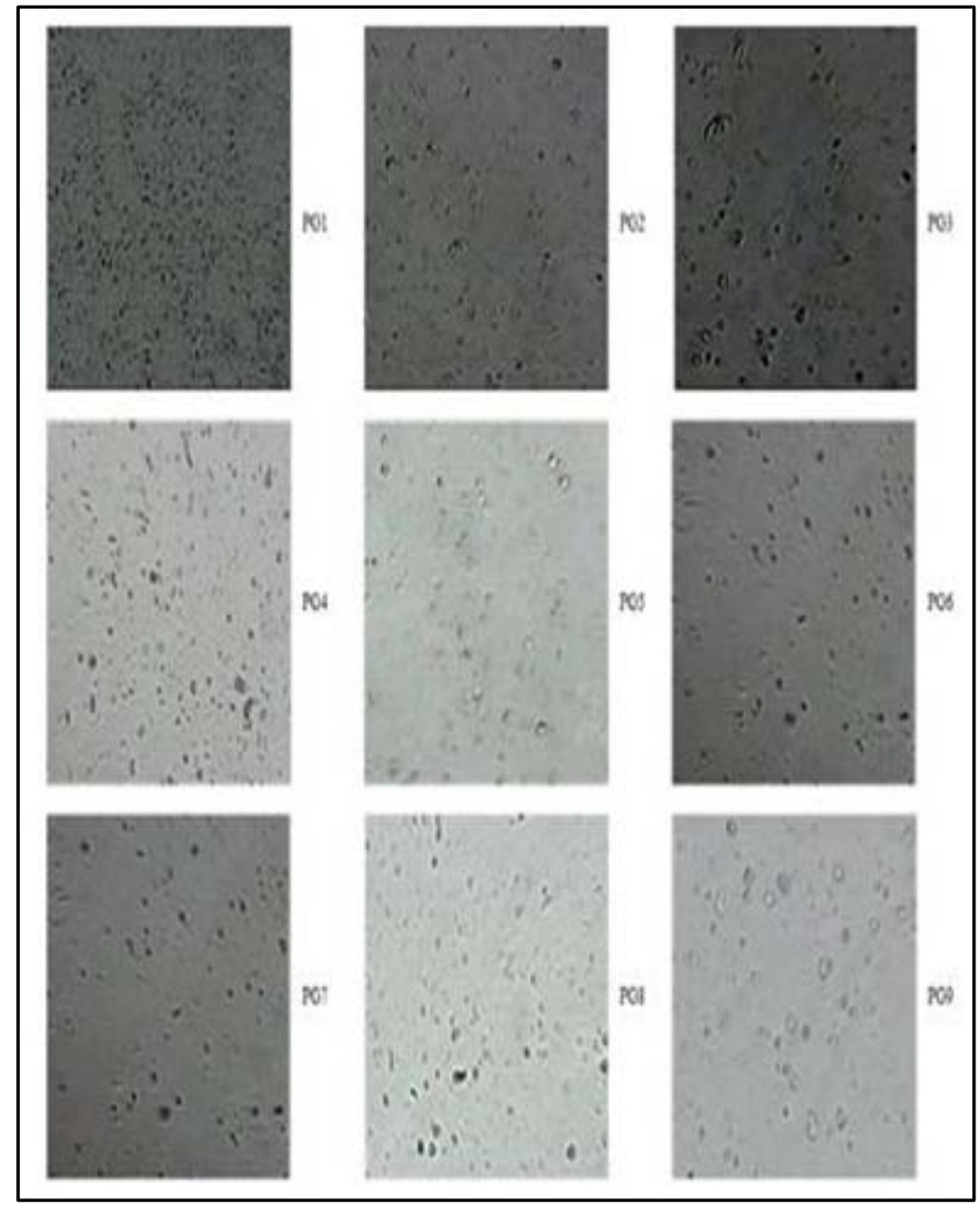

Fig. 1: Photomicrographs of prepared formulations

\section{Percentage entrapment efficiency}

Entrapment efficiency of proniosomes formulations ranged from $38.31 \%$ to $77.96 \%$. The drug encapsulation efficiency of all nine formulations is shown in table 3. PG3 formulation had showed good encapsulation efficiency. The effect of concentration of lecithin on entrapment efficiency is shown in table 3. Increase in lecithin concentration increases percentage entrapment efficiency. This might 
be due to lecithin containing long hydrocarbon chain of lecithin [15, 17]. Therefore they increase the vesicle size of niosomes and increase percentage entrapment efficiency [17]. Effect of amount of surfactant on entrapment efficiency. Initially increase the concentration of surfactant i.e. span 60 might be increased number of niosomes formed because of the volume of hydrophobic domain increases, hence increasing entrapment efficiency. However further increase in the concentration of surfactant decrease entrapment efficiency.

It might be due to formation of mixed micelles along with niosomal vesicles which leads fewer amount of drug might be entrapped inside the vesicle. This leads to lower entrapment efficiency [18].

Table 3: Entrapment efficiency of proniosomes formulations

\begin{tabular}{lll}
\hline S. No. & Formulation code & \%EE* \\
\hline 1 & PG1 & $38.31 \pm 0.05$ \\
2 & PG2 & $64.06 \pm 0.03$ \\
3 & PG3 & $77.96 \pm 0.06$ \\
4 & PG4 & $44.92 \pm 0.01$ \\
5 & PG5 & $72.14 \pm 0.04$ \\
6 & PG6 & $60.12 \pm 0.02$ \\
7 & PG7 & $61.55 \pm 0.05$ \\
8 & PG8 & $66.67 \pm 0.01$ \\
9 & PG9 & $76.49 \pm 0.03$ \\
\hline
\end{tabular}

${ }^{*}$ Above values indicate mean \pm SD $(n=3)$

\section{Vesicle size analysis}

The particle size was found in the ranged from $153.1 \pm 0.03$ to $435.9 \pm 0.04$ as shown in table 4 . proniosomes prepared by using combination of span 60 and lecithin showed increase in particle size at the optimum concentration. These results suggest that addition of lecithin leads to increase in particle size. This might be due to the lecithin contains long hydrocarbon chains $[17,19]$. The relationship observed between proniosomes size and hydrophobicity has been attributed to the decrease in surface energy with increase in hydrophobicity, resulting in the smaller vesicles. The larger vesicles size of proniosomes prepared with high concentration of lecithin which has much lower hydrophobicity than the high concentration of span 60 . Because increase in amount of span 60, increase in hydrophobicity which leads to decrease in vesicle size. The differences in vesicle size among the proniosomes prepared with different ratio of span 60 and lecithin [20].

All formulations showed low value of polydispesity index. Polydispesity index is the ratio of standard deviation to the mean particle size and it signifies the uniformity of particle size within the formulation. The polydispesity values of formulation were found $<1$ (0.428-0.746). It indicates that narrow distribution and uniformity of particle size within formulation $[7,15]$.

\section{Zeta potential determination}

Zeta potential of optimized formulation i.e. PG3 formulations is shown in fig. 3. The value of zeta potential was found to be- $31.18 \mathrm{mV}$ and hence it indicates that the prepared formulations was stable [20].

Table 4: Particle size analysis of proniosomes formulations

\begin{tabular}{llll}
\hline S. No. & Formulation code & Particle size* $(\mathbf{n m})$ & PDI \\
\hline 1 & PG1 & $153.1 \pm 0.03$ & 0.428 \\
2 & PG2 & $290.3 \pm 0.01$ & 0.470 \\
3 & PG3 & $404.5 \pm 0.02$ & 0.746 \\
4 & PG4 & $156.6 \pm 0.05$ & 0.450 \\
5 & PG5 & $365.8 \pm 0.08$ & 0.590 \\
6 & PG6 & $349.7 \pm 0.03$ & 0.673 \\
7 & PG7 & $349.7 \pm 0.05$ & 0.673 \\
8 & PG8 & $357.4 \pm 0.01$ & 0.631 \\
9 & PG9 & $435.9 \pm 0.04$ & 0.600 \\
\hline
\end{tabular}

*Above values indicate mean \pm SD $(n=3)$

Table 5: Zeta potential distribution of optimized formulation (PG3 formulation)

\begin{tabular}{lll}
\hline S. No. & Formulation code & Zeta potential (mV) \\
\hline 1 & PG3 & -31.18 \\
\hline
\end{tabular}

\section{In vitro ex-vivo permeation study}

The PG3 and PG9 formulation showed a more permeation of drug78.39 $\pm 0.05 \%$ and $80.06 \pm 0.01 \%$ respectively over the period of $24 \mathrm{~h}$ through dialysis membrane as compared to other formulations and carbopol gel containing pure NS as it contains more concentration of lecithin $[3,15,17]$. But this formulation was less viscous as shown in table 2 . The PG3 formulation showed optimum drug release due to the optimum concentration of span60 and lecithin. On the basis of entrapment efficiency, in vitro drug diffusion study through the dialysis membrane, spreadability, and viscosity, the formulation PG3 (combination of span 60 and lecithin) was concluded as optimized formulation. Hence PG3 formulation was further subjected to ex-vivo permeation studies. The cumulative drug diffusion of NS carbopol gel and PG3 formulation through human cadaver skin in phosphate buffer $\mathrm{pH} 7.4$ was found to be $17.93 \pm 0.04 \%$ and $63.76 \pm 0.01$ respectively over the period of $24 \mathrm{~h}$.

Fig. 2 and 3 revealed that the proniosomal gel formulation had highest cumulative amount of drug diffusion as compared to carbopol containing pure Neomycin Sulphate. It might be due to the vesicles acts as penetration enhancers to reduce the barrier properties of stratum corneum $[7,21]$. The possible reason for niosomes to enhance the permeability of drug through the skin is depends upon structure of 
skin. Formulation contains surfactant and phospholipid. The phospholipid is fluidizing both the vesicle and the SC lipids such as ceramides etc. and surfactant i.e. span 60 forms the vesicles are more flexible. Phospholipid disturbs structure of the intracellular lipid bilayers in stratum corneum (SC) and increases their fluidity. Niosomes are entered into disturbed SC bilayers through the skin lipids. Thus, resulting the drug release from niosomal vesicles in skin due to the fusion vesicles with skin lipids $[7,14,21,22]$.

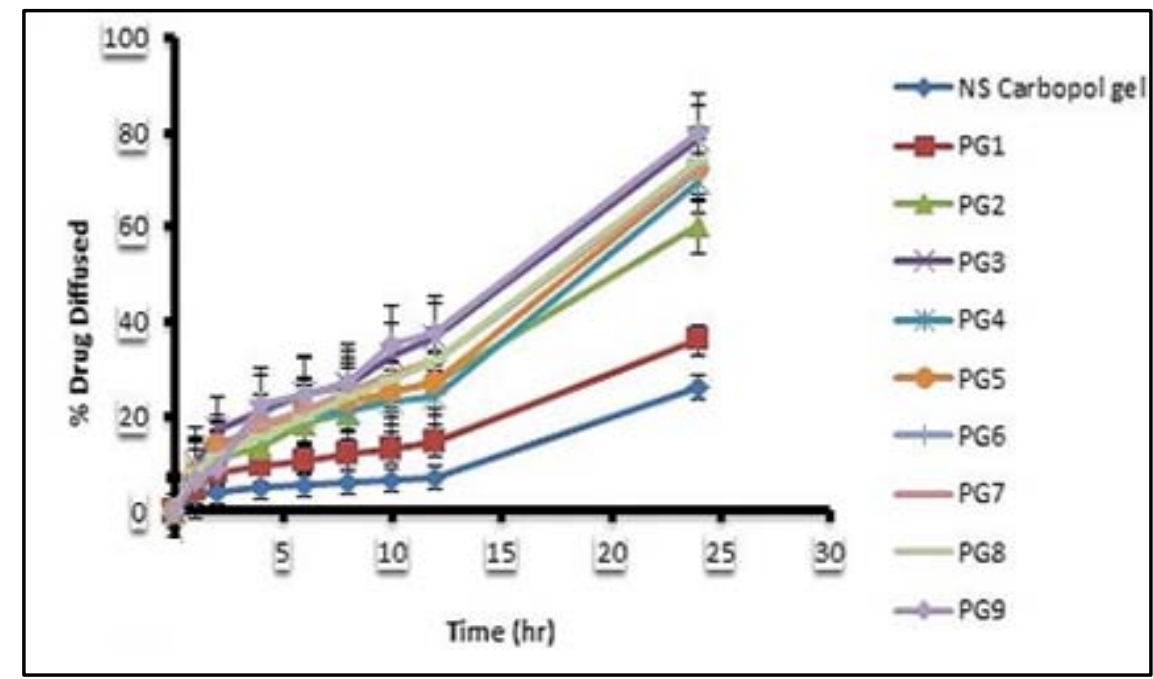

Fig. 2: In vitro drug diffusion study of prepared formulations

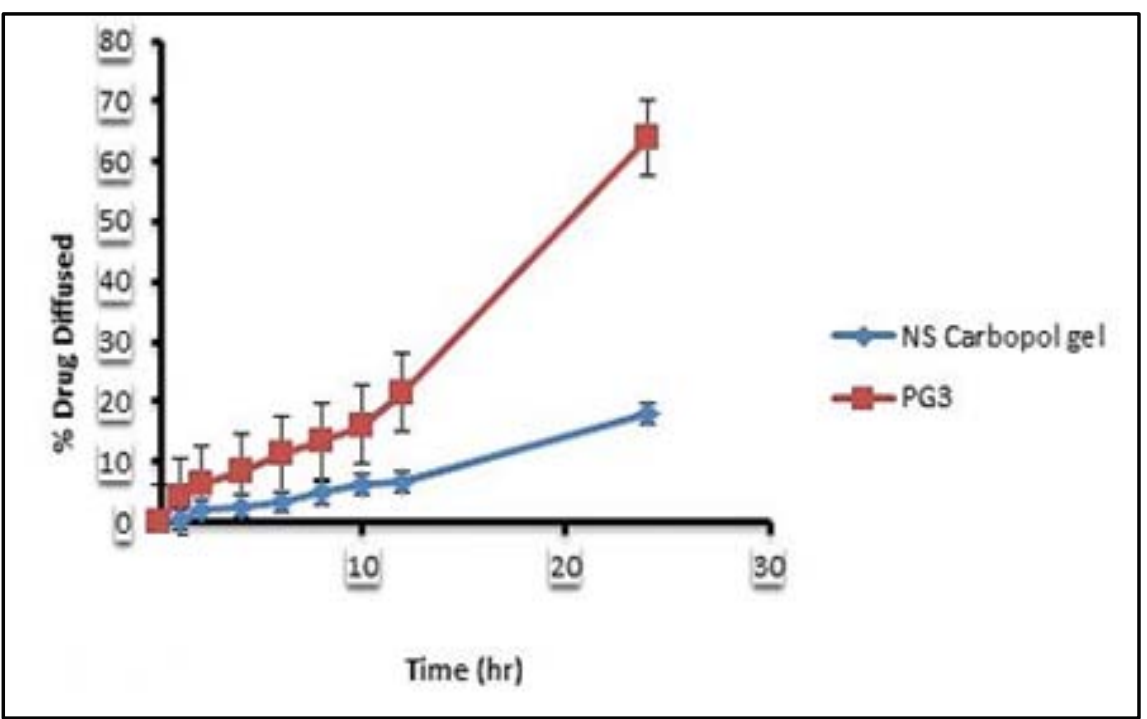

Fig. 3: Comparative diffusion study of plain and proniosomal gel

\section{Kinetics of drug release}

Table 6 represents the value of $\mathrm{R}^{2}$ for PG3 formulations was found higher i.e. 0.926 for zero order model. Hence the zero order models mostly fitted the in vitro release profile of NS proniosomal gel formulation. The value of diffusion exponent (slope) $n$ was found to be 2.422. Therefore, the drug release rate from PG3 formulation was controlled predominantly by super case II transport diffusion [14].

Table 6: Release Kinetic data of PG3 formulation

\begin{tabular}{lllllll}
\hline S. No. & Formulation code & \multicolumn{2}{l}{ Regression coefficient $\left(\mathbf{R}^{2}\right)$} & & \\
\cline { 3 - 7 } & & Zero order & First order & Higuchi model & Hixon crowell model & Korsmeyer-peppas model \\
\hline 1 & PG3 & 0.926 & 0.611 & 0.889 & 0.750 & 0.807 \\
\hline
\end{tabular}

\section{Statistical data}

The variation in the concentration of lecithin significantly affects the entrapment efficiency and percentage drug diffusion $(p<0.05)$. Fig. 4 and 5 represent that entrapment efficiency and \% drug diffusion depends upon both surfactant and lecithin. 3D response surface plots give a representation of the variations in each response when the two factors are simultaneously changed from lower to different factor levels. It also gives the variation in design points from the predicted response value [23-25]. 


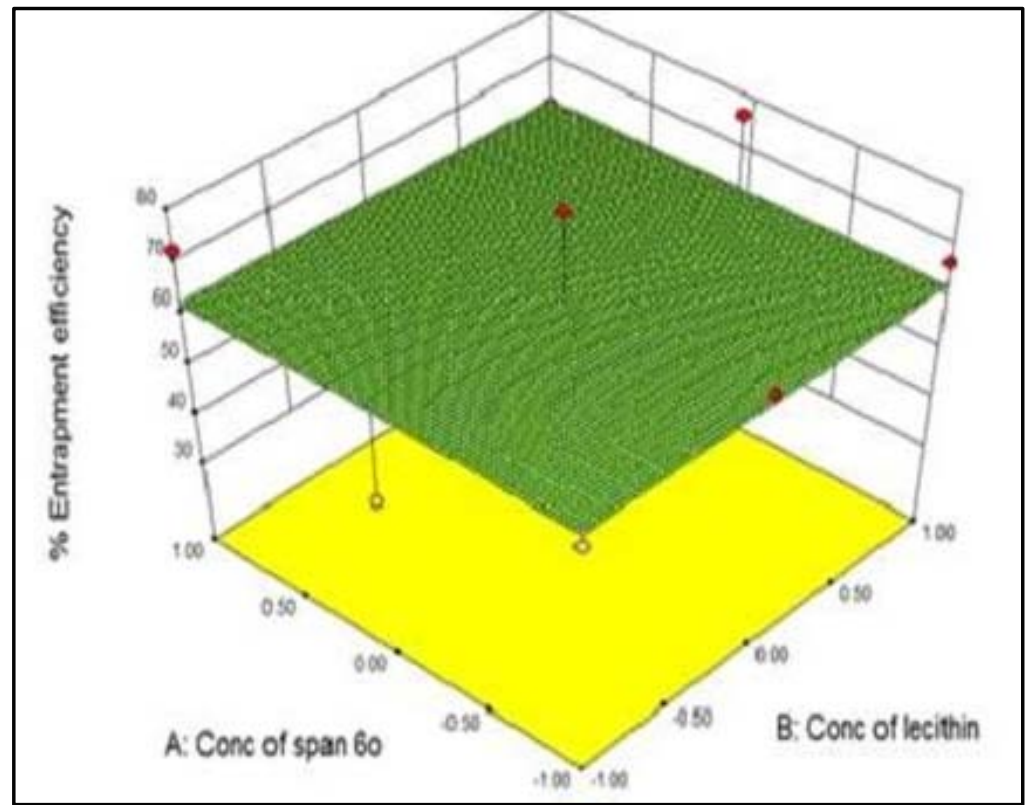

Fig. 4: 3 D surface response plot of effect of concentration of lecithin and span 60 on entrapment efficiency

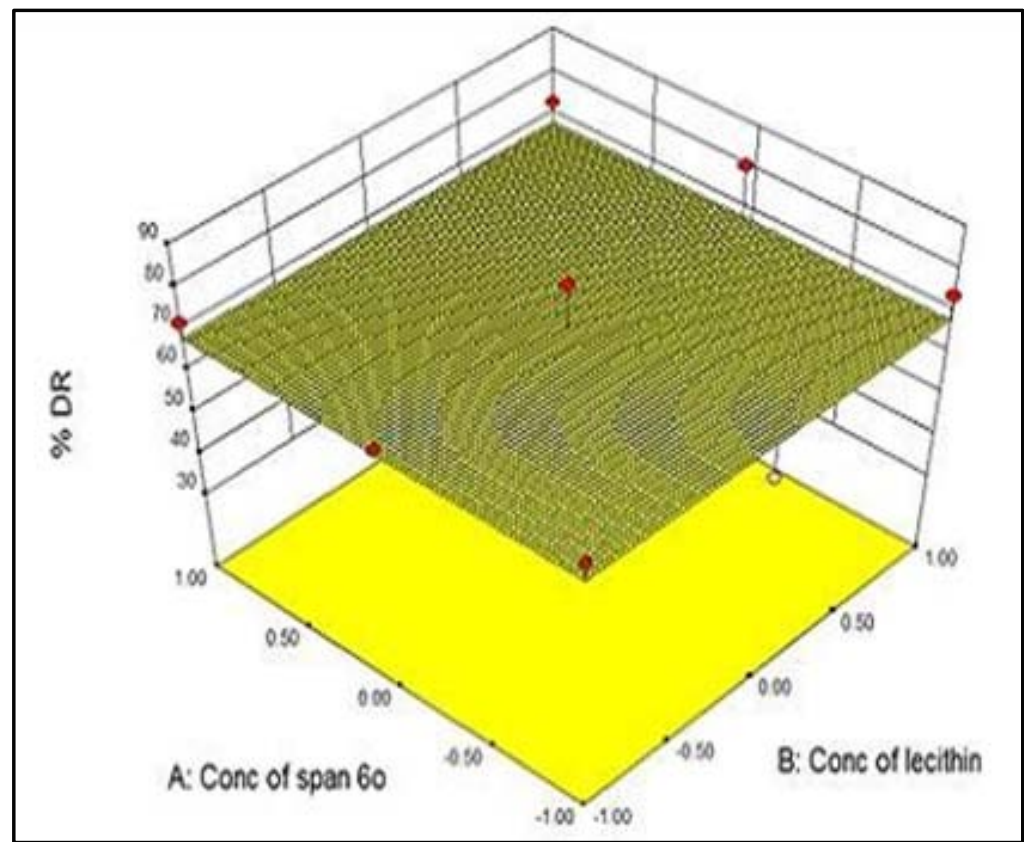

Fig. 5: 3 D surface response plot of effect of concentration of lecithin and span 60 on drug release or diffusion

\section{In vitro antimicrobial activity}

The microbial activity studies showed greater potential of vesicular system (in comparison to marketed cream formulation) to inhibit the growth of Staphylococcus aureus. The zone of inhibition values of proniosomal gel formulation (PG3), marketed formulation (MK) and standard NS solution were found to be $13 \pm 0.01,12.4 \pm 0.04$ and $12 \pm 0.02 \mathrm{~mm}$, respectively as shown in table 7 [26-27].

The enhanced antimicrobial activity of NS may be attributed to enhanced penetration of vesicles containing NS through bacterial cell wall to inhibit protein synthesis its essential for growth of bacteria [8]. The result indicates that the proniosomal formulation is better carrier system for the efficient skin delivery of NS [14].

\section{Stability study}

The sample was analyzed for entrapment efficiency by using centrifugation method, in vitro diffusion study, physical appearance and consistency by using optical microscopy. From the results, it was revealed that consistency of proniosomal gel slightly changed after one month. It might be due to the loss of alcohol present in formulation [14]. Entrapment efficiency and in vitro drug diffusion of proniosomal gel was found to be $75.43 \%$ and $77.12 \%$ respectively after one month as shown in table 8 [14-15].

\section{Skin irritation study}

No erythema was found after $24 \mathrm{~h}$ when optimized formulation PG3 was applied on dorsal surface of rat shown in fig. 6 . The rats were kept under observation for $24 \mathrm{~h}$ [13]. 
Table 7: Zone of Inhibition of different formulations

\begin{tabular}{lllll}
\hline S. & Concentrations & Zone of inhibition & & \\
\cline { 2 - 4 } No. & $(\boldsymbol{\mu g} / \mathbf{m l})$ & Std. $\mathbf{N S}$ solution $(\mathbf{m m})$ & PG3 formulation $(\mathbf{m m})$ & Marketed formulation $(\mathbf{m m})$ \\
\hline 1 & $100 \mu \mathrm{g} / \mathrm{ml}$ & $12 \pm 0.02$ & $13 \pm 0.01$ & $12.4 \pm 0.04$ \\
2 & $50 \mu \mathrm{g} / \mathrm{ml}$ & $10 \pm 0.05$ & $11 \pm 0.03$ & $11 \pm 0.01$ \\
\hline
\end{tabular}

*Above values indicate mean \pm SD $(n=3)$

Table 8: Stability data of proniosomal gel formulation PG3 at room temperature

\begin{tabular}{llll}
\hline S. No. & Parameter & Initial* $^{*}$ & After 1 mo* $^{*}$ \\
\hline 1 & \% EE & $77.96 \%$ & $75.43 \%$ \\
2 & In vitro diffusion study & $78.39 \%$ & $77.12 \%$ \\
\hline
\end{tabular}

*Above values indicate mean $(\mathrm{n}=3)$

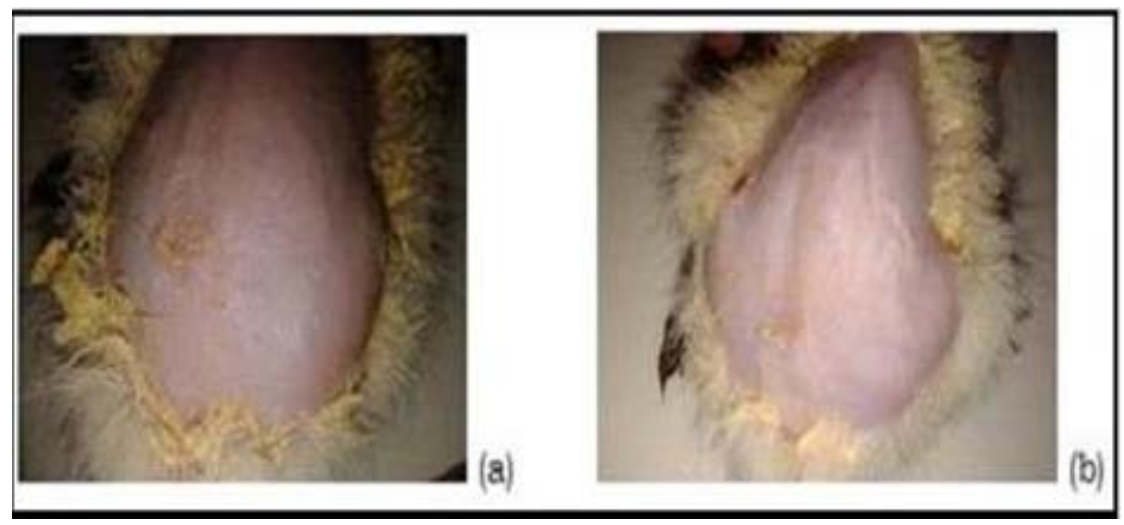

Fig. 6: Skin irritation test a. Before application b. After 24 h. of application of formulation PG3

\section{CONCLUSION}

Proniosomal gel formulated by using combination of span 60, lecithin and cholesterol and carbopol 934 can be used to enhance skin delivery of Neomycin Sulphate because of excellent permeation of drug. The PG3 formulation showed good entrapment efficiency as well as optimum drug release during diffusion experiments with optimum ratio of span 60 and lecithin. The microbiological studies revealed that the optimized formulation (PG3) was more active against staphylococcus aureus species than the standard solution of NS and marketed cream formulation of NS,no skin irritation and good stability. The studies have been shown the promising results; hence there is feasibility of delivery of NS through the topical gel. Thus, the developed topical proniosomal formulation may prove to be a promising carrier for NS.

\section{AUTHORS CONTRIBUTIONS}

All the authors have contributed equally

\section{COMPETING INTERESTS}

The authors declare that they have no competing interests

\section{REFERENCES}

1. Prasad V, Chaurasia S. Performance evaluation of non-ionic surfactant based tazarotene encapsulated proniosomal gel for the treatment of psoriasis. Mater Sci Eng C 2017;1:168-76.

2. Thomas L, Jose S, George SJ, Vidya V. Provesicular niosomes gel: a novel absorption modulator for transdermal delivery. Int J Drug Dev Res 2011;3:58-69.

3. Gamal M. Proniosomes as a drug carrier for transdermal delivery of meloxicam. Bull Pharm Sci 2010;2:131-40.

4. Mehta M, Dureja H, Garg M. Development and optimization of boswellic acid-loaded proniosomal gel. Drug Delivery 2016;23:3072-81.

5. Malakar J, Datta PK, Dey S, Gangopadhyay A, Nayak A. Proniosomes: a preferable carrier for drug delivery system. Elixir Pharm 2011;40:5120-4.
6. Fouda NH, Abdelrehim RT, Hegazy DA, Habib BA. Sustained ocular delivery of dorzolamide-HCl via proniosomal gel formulation: in vitro characterization, statistical optimization, and in vivo pharmacodynamic evaluation in rabbits. Drug Delivery 2018;25:1340-9.

7. Darwhekar G, Jain D, Choudhary A. Elastic liposomes for delivery of neomycin sulphate in deep skin infection. Asian J Pharma Sci 2012;7:230-40

8. D Akanksha, G Vikas, J Neetesh K, S Shailendra. Formulation and evaluation of neomycin sulphate ointment containing natural wound healing agent curcuma longa. Int J Pharma Sci Drug Res 2009;1:116-8.

9. G Sandhyarani, K Praveen Kumar. Formulation and evaluation of neomycin sulphate ointment containing natural wound healing agent couroupita guianensis. Eur J Pharma Sci Res 2014;1:17-20.

10. Srisom $P$, Liawruangrath $B$, Liawruangrath $S$, Slater J. Simultaneous determination of neomycin sulfate and polymyxin b sulfate by capillary electrophoresis with indirect UV detection. J Pharma Biomed Anal 2007;43:1013-8.

11. Fang JY, Yu SY, Wu PC, Huang YB, Tsai YH. In vitro skin permeation of estradiol from various proniosomes formulation. Int J Pharm 2001;215:91-9.

12. Mokhtar M, Omaima AS, Hammad M, Megrab N. Effect of some formulation parameters on flurbiprofen encapsulation and release rates of niosomes prepared from proniosomes. Int J Pharm 2008;361:104-11.

13. Patil H, Hardikar S, Bhosale A. Formulation development and evaluation of proniosomal gel of carvedilol. Int J Pharm Pharm Sci 2012;4:191-7.

14. Singla S, Harikumar SL, Aggarwal G. Proniosomes for effective topical delivery of clotrimazole: development, characterization and performance evaluation. Asian J Pharma Sci 2012;7:259-70.

15. Alam M, Baboota S, Kohli K, Ali J, Ahuja A. Pharmacodynamic evaluation of proniosomal transdermal therapeutic gel containing celecoxib. Sci Asian 2010;36:305-11. 
16. S Pankaj, T Rini, Dandagi PM. Formulation and evaluation of proniosome based drug delivery system of the antifungal drug clotrimazole. Int J Pharma Sci Nanotech 2013;6:1945-51.

17. B Rita, PK Lakshmi. Preparation and evaluation of modified proniosomal gel for localised urticaria and optimisation by statistical method. J Appl Pharma Sci 2012;2:85-91.

18. Shamsheer A, Sabareesh M, Khan P, Sai Krishna P, Sudheer B. Formulation and evaluation of lisinopril dihydrate transdermal proniosomal gels. J Appl Pharma Sci 2011;1:181-5.

19. Hanan M, El-Laithy, Shoukry O, Mahran LG. Novel sugar esters proniosomes for transdermal delivery of vinpocetine: preclinical and clinical studies. Eur J Pharma Biopharma 2011;77:43-55.

20. Singh S, Trivedi S, Jain S. Design and development of proniosome based transdermal delivery of ondansetron hydrochloride. Int J Pharma Bio Res 2012;3:191-201.

21. Azeem A, Ahmad FJ, Talegaonkar S. Explorationof skin permeation mechanism of frusemide with proniosomes. Pharmazie 2009;64:735-40.
22. Alsarra IA, Bosela A, Ahmed SM, Mahrous GM. Proniosomes as a drug carrier for transdermal delivery of ketorolac. Eur J Pharmand Biopharm 2005;59:485-90.

23. Thomas L, Viswanad V. Formulation and optimization of clotrimazole-loaded proniosomal gel using $3^{2}$ factorial design. Sci Pharm 2012;80:731-48.

24. Padamwar MN, Pokharkar VB. Development of vitamin loaded topical liposomal formulation using factorial design approach: drug deposition and stability. Int J Pharm 2006;320:37-44.

25. Patel J, Patel D, Raval J. Formulation and evaluation of propranolol hydrochloride-loaded carbopol-934/ethyl cellulose mucoadhesive microspheres. Iranian J Pharma Res 2010;9:221-2.

26. Guntupalli C, Ramaiah C, Suresh babu C. A field survey and an in vitro study of neomycin ointments. Int J Pharmacol Ther 2013;3:15-23.

27. Badawi A, Elnabarawi M, Elrehem M, Fayed B. Formulation and evaluation of dispersed permethrin proniosomes in powder and microemulsion-based hydrogel bases for the treatment of scabies. Int J Pharm Pharm Sci 2016;8:221-9. 